\title{
BMJ Open Rationale and protocol for the 7- and 8- year longitudinal assessments of eye health in a cohort of young adults in the Raine Study
}

\author{
Samantha Sze-Yee Lee (D) , ${ }^{1}$ Gareth Lingham (1) , ${ }^{2}$ Seyhan Yazar, ${ }^{1,3}$ \\ Paul G Sanfilippo, ${ }^{4}$ Jason Charng, ${ }^{1}$ Fred K Chen, ${ }^{1,5}$ Alex W Hewitt, ${ }^{4,6}$ Fletcher Ng, ${ }^{2}$ \\ Christopher Hammond, ${ }^{7}$ Leon M Straker, ${ }^{8}$ Peter R Eastwood, ${ }^{9,10}$ \\ Stuart MacGregor, ${ }^{11}$ Kathryn A Rose,${ }^{12}$ Robyn M Lucas (D) , ${ }^{13}$ \\ Jeremy A Guggenheim (D) , ${ }^{14}$ Seang-Mei Saw, ${ }^{15,16}$ Minas T Coroneo, ${ }^{17}$ \\ Mingguang He, ${ }^{4,18}$ David A Mackey ${ }^{1,4}$
}

To cite: Lee SS-Y, Lingham G, Yazar S, et al. Rationale and protocol for the 7and 8-year longitudinal assessments of eye health in a cohort of young adults in the Raine Study. BMJ Open 2020;10:e033440. doi:10.1136/ bmjopen-2019-033440

- Prepublication history for this paper is available online To view these files, please visit the journal online (http://dx.doi org/10.1136/bmjopen-2019033440).

Received 08 August 2019 Revised 23 January 2020 Accepted 04 March 2020
Check for updates

(C) Author(s) (or their employer(s)) 2020. Re-use permitted under CC BY-NC. No commercial re-use. See rights and permissions. Published by BMJ.

For numbered affiliations see end of article.

Correspondence to Dr Samantha Sze-Yee Lee; samantha.sy.lee29@gmail.com

\section{ABSTRACT}

Introduction Eye diseases and visual impairment more commonly affect elderly adults, thus, the majority of ophthalmic cohort studies have focused on older adults. Cohort studies on the ocular health of younger adults, on the other hand, have been few. The Raine Study is a longitudinal study that has been following a cohort since their birth in 1989-1991. As part of the 20-year follow-up of the Raine Study, participants underwent a comprehensive eye examination. As part of the 27and 28-year follow-ups, eye assessments are being conducted and the data collected will be compared with those of the 20-year follow-up. This will provide an estimate of population incidence and updated prevalence of ocular conditions such as myopia and keratoconus, as well as longitudinal change in ocular parameters in young Australian adults. Additionally, the data will allow exploration of the environmental, health and genetic factors underlying inter-subject differential long-term ocular changes

Methods and analysis Participants are being contacted via telephone, email and/or social media and invited to participate in the eye examination. At the 27-year followup, participants completed a follow-up eye screening, which assessed visual acuity, autorefraction, ocular biometry and ocular sun exposure. Currently, at the 28year follow-up, a comprehensive eye examination is being conducted which, in addition to all the eye tests performed at the 27-year follow-up visit, includes tonometry, optical coherence tomography, funduscopy and anterior segment topography, among others. Outcome measures include the incidence of refractive error and pterygium, an updated prevalence of these conditions, and the 8-year change in ocular parameters.

Ethics and dissemination The Raine Study is registered in the Australian New Zealand Clinical Trials Registry. The Gen2 20-year, 27-year and 28-year follow-ups are approved by the Human Research Ethics Committee of the University of Western Australia. Findings resulting from the study will be published in health or medical journals and presented at conferences.
Strengths and limitations of this study

- The eye examinations in the follow-ups include a comprehensive eye imaging and follow standardised protocols which allow appropriate longitudinal comparison.

- A myriad of measures (eg,cardiovascular, sleep and activity and genetics) from a multidisciplinary team have been collected from this sample of young adults since their prenatal periods.

- The longitudinal nature of the Raine Study has advantages compared with cross-sectional studies in terms of inferring causality from its observations.

- Minimising attrition remains a challenge; however, the dropout rates for the Raine Study have been low compared with many other longitudinal studies and improvements in communication technology will allow us to better contact participants and schedule them for visits.

Trial registration number ACTRN12617001599369; Active, not recruiting.

\section{INTRODUCTION}

For most activities in our everyday lives, such as reading, driving and food preparation, we require good vision. ${ }^{1-9}$ When vision is impaired-a common consequence of eye diseases-quality of life, mobility and independence are often impacted. ${ }^{10-13}$ In the year 2015 , approximately $0.5 \%$ of the world population suffered from blindness (based on presenting visual acuity (VA) of worse than 6/120), while an additional $3.0 \%$ had moderate or severe visual impairment (presenting VA of worse than $6 / 18$ but better than 6/120). ${ }^{14}$ Eye diseases and visual impairment more commonly affect elderly 
adults: $52 \%$ of individuals with blindness and $38 \%$ with moderate or severe visual impairment are aged 70 years or above. ${ }^{14}$ Thus, the vast majority of ophthalmic cohort studies have focused on older adults, ${ }^{15}$ including several longitudinal studies that followed, or are following, their respective cohorts through periods of up to 15 years. ${ }^{16-29}$ The findings from such studies have provided reference figures for the incidence and prevalence of eye conditions or visual impairment in older adults of the general population, ${ }^{17} 2025-2730-45$ as well as the natural progression of eye diseases. ${ }^{46-50}$

Prospective cohort studies on the ocular health of younger adults, on the other hand, have been limited. This gap in the literature is significant as such studies would be valuable for delineating the trajectory of changes in ocular health and biometry from young adulthood, when ocular health is expected to be at its peak, to old age, when eye diseases and visual impairment are more prevalent. Furthermore, the outcome and impact of childhood eye conditions should be measured during young adulthood, ${ }^{51}$ which is when eye conditions that developed during childhood, such refractive errors, typically stabilise.

To date, only a handful of longitudinal studies have been conducted on the ocular health or biometry of young adults. Kinge et $a \tilde{l}^{253}$ and Jorge $e t a b^{5455}$ followed a cohort of university students in Norway and Portugal, respectively, over a 3-year period. These studies reported on changes in refractive errors, binocular vision and other ocular parameters in young adults completing a university degree ${ }^{52-56}$ However, university students are not representative of the general population of young adults, especially given the well-established link between higher education and myopia or longer axial length. ${ }^{57-59}$ The Correction of Myopia Evaluation Trial (COMET) followed over 300 children with myopia aged 6-12 years through to young adulthood, tracking changes in refractive error, corneal curvature and axial length over a 14-year period. ${ }^{60}$ Like the Norwegian and Portuguese studies, the findings from COMET may not be relevant to the general population given that the participants were mostly myopic.

\section{The Raine Study}

The Raine Study is an ongoing prospective study that began as a randomised, controlled trial investigating the value of intensive ultrasound imaging during pregnancy on the health outcomes of the offspring. ${ }^{6162}$ Between May 1989 and November 1991, pregnant women presenting at the public antenatal clinic at the King Edward Memorial Hospital were recruited to participate in the trial. A total of 2900 pregnant women enrolled in the study at 16-18 weeks of gestation, from whom, 2868 offspring were born. Since then, these offspring have been undergoing a series of medical examinations and completing questionnaires at various ages; the types of health or medical measurements and the age at which they were measured are detailed in Straker et al. ${ }^{62}$ This randomised controlled trial thus evolved into a longitudinal study able to investigate how events during pregnancy and childhood affect health outcomes later in life, and to track changes in health status through childhood and earl adulthood. This longitudinal study was initially focused on the cohort born in 1989-1992 (termed Generation2). ${ }^{62}$ Later, the children (Gen3), parents (Gen1) and grandparents (Gen0) of the original cohort have been enrolled as participants in the Raine Study, forming a multigenerational longitudinal study.

At the 20-year follow-up of the Raine Study, between 2010 and 2012, a comprehensive eye examination was conducted at the Lions Eye Institute. ${ }^{63}$ A total of 1344 participants (51.3\% man) of the Raine Gen2 completed the eye examination as well as a detailed questionnaire on ocular and general health history. Findings from the eye examinations at the 20-year follow-up allowed us to characterise the ocular parameters-including optic disc measures, ocular sun exposure and refractive error ${ }^{64-67}-$ of healthy young adults, as well as document the systemic, environmental or genetic factors that could affect these measures. ${ }^{64-87}$

\section{Study aims}

As a follow-up to the eye examination conducted at the 20-year follow-up, a screening eye test was conducted as part of the 27-year follow-up of the Raine Study (primarily focused on cardiovascular health). This is currently being followed by a more comprehensive eye examination as part of the 28-year follow-up. The primary aim of the follow-up studies is to document the longitudinal change in ocular parameters during young adulthood, with a focus on refractive error, retinal thickness and optic disc changes. Changes within a short-term period (1 year; between the 27- and 28-year follow-ups; principally for non-cycloplegic refraction) and a longer-term (8 years; between the 20and 28-year follow-ups) will be determined.

Secondary aims include:

1. To provide updated age- and sex-standardised prevalence and incidence estimates of refractive errors, pterygium and other ocular conditions in a population of young adults.

2. To explore the environmental, genetic and systemic factors underlying the development or progression of refractive errors and ocular conditions during young adulthood.

3. To explore the environmental, genetic and health factors underlying the changes in ocular parameters during young adulthood.

This paper describes the rationale and methodology of the 7-year and 8-year longitudinal eye health assessments performed at Raine Study 27- and 28-year follow-ups.

\section{METHODS AND ANALYSIS}

\section{Study participants recruitment and involvement}

Of the original cohort of 2868 Gen2 participants, 1994 have previously given consent to be contacted for review 


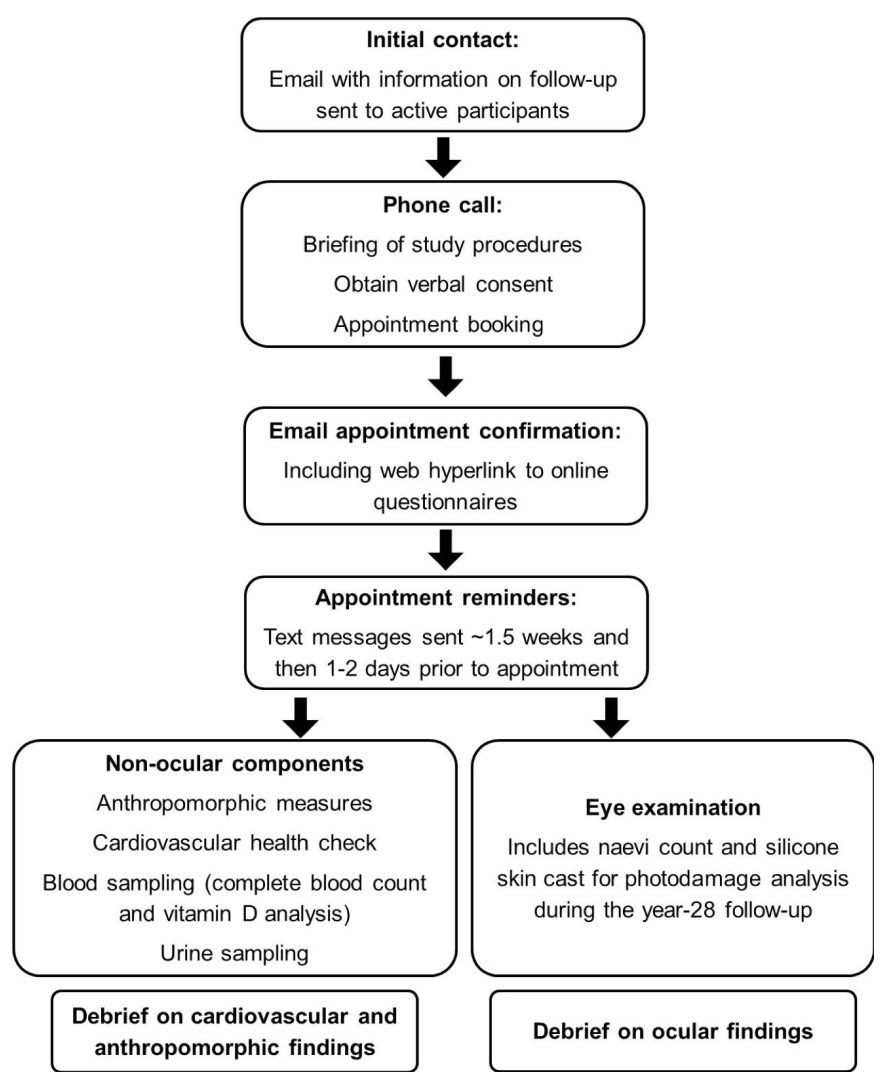

Figure 1 Overview of booking and assessment procedure for the follow-ups.

at the 27-year follow-up and are considered 'active'. All active participants were invited to attend an eye screening during their visit for a cardiovascular health assessment (figure 1).

For the 28-year follow-up, there are 1985 active participants to be contacted and invited to attend a comprehensive eye examination and other health assessments (separate to the eye examination; figure 1). Although the main aim of the study is to evaluate the change in ocular parameters between the 20-, 27- and 28-year time periods, all participants, regardless of whether they attended the 20-year eye health assessments, are invited. There are no inclusion or exclusion criteria as we also aim to capture representative data for the general population. An outline of the booking and assessment procedures for the 27 - and 28-year follow-ups is shown in figure 1.

\section{Questionnaire}

Participants complete a self-administered questionnaire online. The comprehensive questionnaire collects information on sociodemographics, education, occupation, physical and mental health, eating habits, smoking, alcohol and drug use, sleeping habits, as well as medical history. Questions that are directly related to ocular health include (1) ocular history, (2) reading/visual habits and (3) ocular sun exposure. Ocular history includes information on personal and family history of eye conditions, such as use of spectacles or contact lenses and previous eye surgery. Reading and other visual habits include time spent on near work, such as looking at mobile phones, computer use, reading, writing and the use of other information technology devices. Ocular sun exposure questions include time spent outdoors and the use of sunglasses.

\section{Eye examination}

The 27-year follow-up was conducted from June 2016 to December 2018 at the Raine Study House, University of Western Australia, Crawley, Australia, and a total of 1084 (age 26-28 years old, 50.7\% women) underwent the eye screening. The eye screening took about $20 \mathrm{~min}$ for each participant to complete.

Study data collection for the 28-year follow-up was started in April 2018 and was planned to run for 24 months. The eye examination is conducted at the Lions Eye Institute, Perth, Australia and takes about 1.5 hours to complete. The description of each test is further detailed below, and the list of eye tests performed at the 27-year and 28-year follow-ups is shown in table 1 .

\section{VA measurement and autorefraction}

Presenting distance VA is measured monocularly using a modified Early Treatment of Diabetic Retinopathy Study (ETDRS) logMAR-style chart (Precision Vision, Woodstock, Illinois, USA) and recorded in Snellen notation. Participants wear their habitual distance visual correction (if any) and are encouraged to read the smallest line they can see. Pinhole VA is then measured for each eye regardless of the level of their presenting VA. Pre-cycloplegic autorefraction/autokeratometry (Nidek ARK-510A, NIDEK Co., Japan) is then conducted and repeated at least $20 \mathrm{~min}$ after instillation of tropicamide $1 \%$ (see Tonometry and mydriasis).

\section{Conjunctival ultraviolet autofluorescence (CUVAF) and eye colour photography}

To obtain objective measures of ocular sun exposure, CUVAF images of the nasal and temporal bulbar conjunctiva are taken using a digital camera (Nikon D100 digital camera, Tokyo Japan) with a $105 \mathrm{~mm} 147 \mathrm{f} / 2.8$ Micro Nikkor lens (Nikon, Melville, New York, USA) fitted with a UV filter (B+W 486 UV IR filter, Schneider Kreuznach, Bad Kreuznach, Rhineland-Palatinate, Germany). This camera system is additionally fitted with two external electronic Metz 36 C-2 flashes (Metz, Zirndorf, middle Franconia, Germany) with UV transmission Wratten glass filters over the flash heads, such that the transmission of the flashes is mostly in the UVA range $(300-400 \mathrm{~nm}$, peak of $365 \mathrm{~nm}$ ). Images are taken in a dark room to ensure that only UV fluorescence is recorded. The area of CUVAF for each participant is than quantified offline using a previously validated MATLAB program. ${ }^{84}$

Close-up and high-resolution colour photographs of each of the participants' eyes are taken using a Nikon D1000 digital camera (Tokyo, Japan) with a $105 \mathrm{~mm}$ 147 f/2.8 Micro Nikkor lens (Nikon, Melville, New York, USA). Three images are taken for each eye: nasal and 
Table 1 Outline of ocular tests performed at the Raine Study follow-ups

\begin{tabular}{|c|c|c|c|}
\hline & $\begin{array}{l}\text { 20-year } \\
\text { (Mar 2010- } \\
\text { Feb 2012) }\end{array}$ & $\begin{array}{l}\text { 27-year } \\
\text { (Jun 2016- } \\
\text { Dec 2018) }\end{array}$ & $\begin{array}{l}\text { 28-year } \\
\text { (Apr 2018- } \\
\text { Apr 2020) }\end{array}$ \\
\hline Questionnaire & $\sqrt{ }$ & $\sqrt{ }$ & $\sqrt{ }$ \\
\hline Visual acuity & $\sqrt{ }$ & $\sqrt{ } \dagger$ & $\sqrt{ } \dagger$ \\
\hline Vernier acuity & $\sqrt{ }$ & & \\
\hline $\begin{array}{l}\text { Contrast } \\
\text { sensitivity }\end{array}$ & $\sqrt{ }$ & & \\
\hline
\end{tabular}

$\begin{array}{ll}\text { Colour vision } & \sqrt{ } \\ \text { Orthoptic } & \sqrt{ }\end{array}$

assessment*

$\begin{array}{llll}\begin{array}{l}\text { Pre-cycloplegic } \\ \text { autorefraction }\end{array} & \sqrt{ } & \sqrt{ } & \sqrt{ } \\ \begin{array}{l}\text { Spectacle lens } \\ \text { measurement }\end{array} & \sqrt{ } & \sqrt{ } \dagger & \sqrt{ } \dagger\end{array}$

$\begin{array}{llll}\begin{array}{l}\text { Eyelid position } \\ \text { photography }\end{array} & \sqrt{ } & & \\ \begin{array}{l}\text { CUVAF } \\ \text { photography }\end{array} & \sqrt{ } & \sqrt{ } & \sqrt{ }\end{array}$

$\begin{array}{llll}\begin{array}{l}\text { Eye colour } \\ \text { photography }\end{array} & \sqrt{ } & \sqrt{ } & \sqrt{ } \\ \begin{array}{l}\text { Ocular biometry } \\ \text { Eyelash length }\end{array} & \sqrt{ } & \sqrt{ } & \sqrt{ } \\ \text { measurement } & & \\ \text { Tonometry } & \sqrt{ } & \sqrt{ } \\ \text { Mydriasis } & \sqrt{ } & \sqrt{ } \ddagger \ddagger \\ \begin{array}{l}\text { Fundus } \\ \text { photography }\end{array} & \sqrt{ } & \sqrt{ } \ddagger \ddagger\end{array}$

$\begin{array}{lll}\begin{array}{l}\text { Retinal } \\ \text { tomography }\end{array} & \sqrt{ } & \\ \text { OCT } & \sqrt{ } & \sqrt{ } \\ \text { OCT-A } & & \sqrt{ } \\ \begin{array}{l}\text { Specular } \\ \text { microscopy }\end{array} & \sqrt{ } & \end{array}$

\begin{tabular}{lll}
$\begin{array}{l}\text { Anterior segment } \\
\text { topography }\end{array}$ & $\sqrt{ }$ & $\sqrt{ }$ \\
$\begin{array}{l}\text { Cycloplegic } \\
\text { autorefraction }\end{array}$ & $\sqrt{ }$ & $\sqrt{ }$ \\
\hline
\end{tabular}

*Includes cover test, ocular motility, stereoacuity, and tests for ocular dominance, nystagmus and microtropia (four dioptre prism test).

†Performed using different equipment from the 20-year follow-up. $\ddagger$ Performed while awaiting full pupil dilation after instillation of mydriatics.

CUVAF, conjunctival ultraviolet autofluorescence; OCT, optical coherence tomography; OCT-A, optical coherence tomography angiography.

temporal conjunctiva, plus an iris-centred photo (primary gaze). These images are used to assess for the presence of pterygia, pinguecula and other conjunctiva or abnormalities, as well as document eye colour.
Ocular biometry

An IOLMaster V.5 (Carl Zeiss Meditec AG, Jena, Germany) is used to obtain measurements of axial length, whiteto-white corneal diameter, keratometry and anterior chamber depth. As per the standard IOLMaster built-in protocol, the mean of five axial length measurements will be used for analyses. Erroneous measurements (eg, extremely high or low values that may be caused by subject movement) and measurements that fall outside one SD of the mean are removed from the computation. The system automatically computes the mean of three keratometry and six anterior chamber depth measurements, while two to three white-to-white measurements are taken and the median of these is recorded.

\section{Tonometry and mydriasis}

Intraocular pressure (IOP) is measured with an ICare rebound tonometer (Icare TAO1i Tonometer, Icare Finland Oy, Helsinki, Finland). The ICare automatically takes six IOP measurements and discards the highest and lowest readings. The average of the four remaining readings is then recorded as the final IOP. As per the ICare tonometry protocol, IOPs are re-measured if the instrument displays an error sign on the final IOP reading or if the IOP is greater than $21 \mathrm{~mm} \mathrm{Hg} .{ }^{88} 89$ Following tonometry, participants' eyes are topically anaesthetised (one drop proxymetacaine hydrochloride $0.5 \%$ ) prior to mydriasis (one drop tropicamide 1.0\%). While awaiting full pupil dilation, fundus photography, optical coherence tomography (OCT) and OCT-angiography (OCT-A) are performed. If full dilation is not achieved after 20 min, another drop of tropicamide is instilled.

\section{Posterior segment: fundus photography and OCT}

A fundus photograph of each eye is taken using a widefield scanning laser device (California, Optos, Dunfermline, UK), which has a resolution of $20 \mu \mathrm{m}$ and able to capture up to a $200^{\circ}$ view of the funds even through an undilated pupil. A spectral-domain OCT (SD-OCT; Spectralis HRA+OCT, Heidelberg Engineering, Heidelberg, Germany) is used for high-resolution imaging of the optic disc and central retina in both eyes. Prior to imaging, autokeratometry data are entered to correct for ocular magnification effects. The instrument's eye-tracking software is used to minimise the effects of eye movements. The protocol for the SD-OCT imaging for each eye is as follows:

a. Disc-centred scans

- Forty-nine-line raster scan of a $15^{\circ} \times 10^{\circ}$ area. The average of nine frames for each B-scan is used to improve quality.

- Peripapillary retinal nerve fibre layer (RNFL) thickness measurements. A circular B-scan of the peripapillary RNFL is taken along a $3.5 \mathrm{~mm}$-diameter $\left(\sim 12^{\circ}\right)$ circle.

- Optic nerve head radial and circle (ONH-RC) scan. Forty-eight equidistant $\left(7.5^{\circ}\right.$ spaced $)$ radials and three circle B-scans are obtained. Each radial B-scan 
is averaged from 25 frames and spans $4.7 \mathrm{~mm}$. The three circular B-scans are $3.5 \mathrm{~mm}\left(\sim 11.5^{\circ}-12.5^{\circ}\right)$, $4.1 \mathrm{~mm}\left(\sim 13.5^{\circ}-14.5^{\circ}\right)$ and $4.7 \mathrm{~mm}\left(\sim 15.5^{\circ}-16.5^{\circ}\right)$ in diameter, respectively, and each of these are averaged from 100 frames. Prior to starting the scans, the ONH-RC programme automatically detects the foveal and Bruch's membrane opening positions. The examiner checks and, if necessary, manually corrects the positions of these landmarks.

b. Foveal-centered scans

- Thirty-one-line raster scan of a $\left(30^{\circ} \times 25^{\circ}\right)$. Each Bscan is averaged from nine frames.

- Enhanced depth imaging of the macular. A horizontal and vertical line scan centred on the fovea is taken for each eye. Each B-scan spans about $8.6 \mathrm{~mm}$ $\left(\sim 30^{\circ}\right)$ and the average of 100 frames for each scan is recorded for analysis.

\section{OCT angiography}

An RTVue XR Avanti system (V.2016.1.0.26; Optovue, Fremont, California, USA) is used to image a $3 \times 3 \mathrm{~mm}$ square centred on the macular and a $4.5 \times 4.5 \mathrm{~mm}$ square centred on the optic disc in both eyes. The instrument utilises a superluminescent diode light source with central wavelength of $840 \mathrm{~nm}$ (bandwidth $45 \mathrm{~nm}$ ) to acquire axial resolution of $5 \mu \mathrm{m}$ in tissue. The OCT-A scanning speed is 70000 A-scans per second. A splitspectrum amplitude-decorrelation angiography (SSADA) algorithm is utilised to generate an OCTA map of the retinal vasclature. ${ }^{90}$ For each scan, a horizontal-priority (fast-X) scan and a vertical-priority (fast-Y) scan are acquired, which is combined to generate one scan by the Optovue software three-dimensional orthogonal registration software (Motion Correction Technology; Optovue) to reduce motion artefacts.

In a subset of participants, OCT-A is also acquired using SD-OCT (Heidelberg Spectralis HRA+OCT as above). The axial resolution of the Spectralis system is $3.9 \mu \mathrm{m}$ and proprietary software (Projection Artifact Removal) is used to reduce noise. A $3 \times 3 \mathrm{~mm}$ acquisition window centred on the fovea is recorded.

\section{Anterior segment topography}

An OCULUS Pentacam (software V.6.08r27; OCULUS Optikgerate GmbH, Wetzlar, Germany) is used to obtain tomography images of the cornea, anterior chamber and crystalline lens. The system uses a rotating Scheimpflug camera to collect elevation data from 25000 points on the cornea to construct a three-dimensional image of the anterior segment.

\section{Non-ocular measures of sun exposure}

In addition to CUVAF and eye colour photography, serum concentration of 25-hydroxy vitamin D $[25(\mathrm{OH}) \mathrm{D}]$ is used as a measure of recent ultraviolet radiation exposure. Blood samples are collected in serum separation tubes during the cardiovascular health assessment and the serum is separated and stored at $-80^{\circ}$ for $25(\mathrm{OH}) \mathrm{D}$ analysis. Two surrogate measures of cumulative sun exposure are used. First, the number of melanocytic naevi on the right arm of each participant is counted by trained examiners using a standardised protocol ${ }^{91}$ Second, a cast of the skin on the back of the right hand is taken using a silicone mould. To assess the level of actinic skin damage, and hence past sun exposure, the skin mould will be graded according to previously described criteria. ${ }^{92}$

\section{Definitions of refractive errors}

As the definition of myopia varies across studies, for the purpose of comparison to our figures in the 20-year follow-up ${ }^{65}$ myopia and high myopia are defined as spherical equivalents of $<-0.50$ dioptres (D) and $<-6.00$ $\mathrm{D}$, respectively. To allow comparisons with other studies, myopia and high myopia are additionally defined as spherical equivalents of $\leq-0.50 \mathrm{D}$ and $\leq-5.00 \mathrm{D}$, respectively, as these are the most commonly used thresholds in studies. ${ }^{93}{ }^{94}$ Hypermetropia and high hypermetropia are defined as spherical equivalents of $\geq+0.50 \mathrm{D}$ and +5.00 $\mathrm{D}$, respectively. ${ }^{42}$ Astigmatism is expressed in minus cylinder, and is considered clinically significant if it is $\geq 1.00 \mathrm{D}$. Given that refraction without cycloplegia may result in underestimation of refraction in some young adults, especially in hyperopic eyes by about $1 \mathrm{D},{ }^{95}$ refractive errors are determined based on the cycloplegic autorefraction.

\section{Patient and public involvement}

Participants were not invited to comment on the study design and aims or to interpret the findings, contribute to the writing or editing of this document.

\section{Statistical analysis}

Data available for participants who complete the 20- and 28-year follow-ups will be included in the analysis for the 8-year longitudinal change in ocular parameters and incidence of eye conditions (figure 2). Additionally, the 1-year incidence of refractive error (non-cycloplegic refraction) and pterygium will be analysed using data from participants who complete the 27- and 28-year follow-ups. Generalised estimating equations will be used to investigate longitudinal change in continuous measures as these are suited for interpreting population-averaged effects, ${ }^{96}$ and can account for missing or non-parametric data. ${ }^{97}$ Potential confounders, such as environmental, systemic, and ocular effects, will be considered in the analyses as appropriate.

To provide an update on the prevalence of eye diseases and refractive error, all 28-year participants will be included. Age and sex standardised prevalence of refractive errors and other ocular conditions, as well as their potential predictors and risk factors, will be calculated. The latter will be expressed in terms of odds ratios that will be assessed using logistic regression models. Statistical analyses will be conducted in R, V.3.4.0 or later (The R Foundation for Statistical Programming, https://www. 


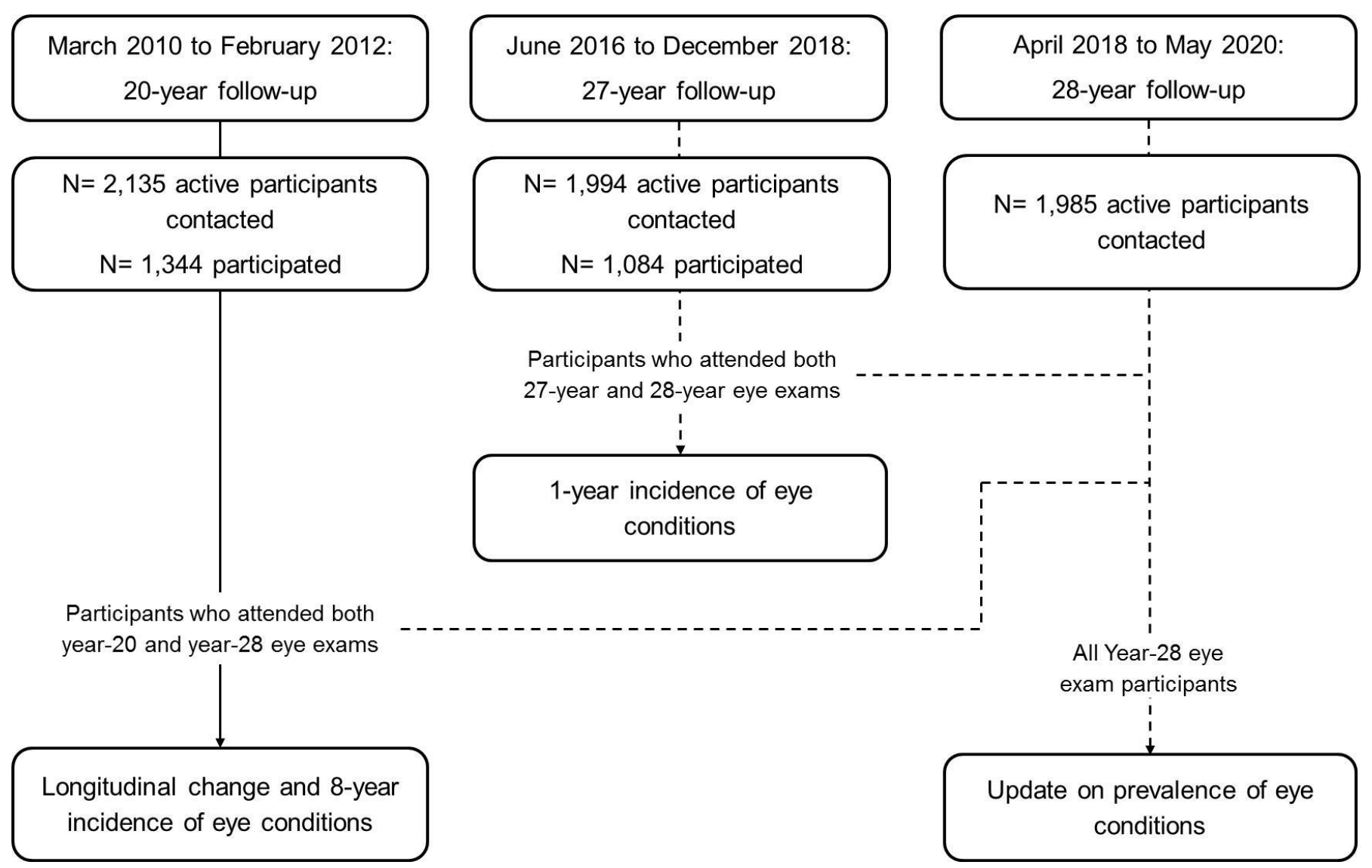

Figure 2 Samples for analyses.

r-project.org/ (open source)), and the level of significance will be set at $\mathrm{p}<0.05$.

\section{Implications}

At the 20-year Raine Study follow-up, conducted between 2010 and 2012, the prevalence of myopia was $23.7 \%$ and of pterygium was $1.2 \%$ in a population of young Australian adults. ${ }^{63}$ 65-67 However, the prevalence of myopia is increasing worldwide, ${ }^{939899}$ with more than half of the Australasia population predicted to by myopic by the year $2050 .^{93}$ Therefore, an update in prevalence of myopia is indicated and this will be addressed by the current study. Additionally, the current study will build on the findings of the 20-year Raine Study follow-up, which included a number of environmental and systemic risk factors for various ocular conditions. ${ }^{677186100}$ While previous Australian studies, including the Blue Mountains Eye Study ${ }^{43} 44$ and the Melbourne Visual Impairment Project, ${ }^{101} 102$ were also landmark epidemiological projects, only older populations were evaluated and the findings therefore cannot be extrapolated to the younger generations. The ongoing Raine Study will form a large longitudinal eye health study in a general population of young adults.

In addition to an update in prevalence of myopia, a major objective of the longitudinal eye health assessments during the Raine Study follow-ups is to evaluate the long-term changes in refractive error. Refractive error, especially myopia, has garnered a tremendous amount of attention in the scientific and general community in the past decade due its rising incidence worldwide. While the natural history of refractive error has been fairly well documented in children and adolescents, ${ }^{103-107}$ refractive change during young adulthood is much less well understood.

The eye health assessments during the Raine Study follow-ups will also evaluate the longitudinal change in optic disc, retinal, anterior segment and other ocular biometry measures. Previous reports on 'age-related changes' in ocular parameters were based largely on crosssectional data in a sample with a wide age range. ${ }^{108-118}$ However, ocular parameters may change not only as a result of age, but also as a result of environmental or generational differences, such as in the case of refractive error. $^{59}$ Longitudinal observations are therefore better placed to show age-related changes compared with crosssectional data. Longitudinal ocular changes will additionally be analysed for associations with environmental, systemic or genetic factors.

\section{Strengths and limitations of the study}

The main strength of the ocular assessments in the Raine follow-up visits is the standardised protocols and the comprehensive ocular imaging, with many of the tests and instruments used similar to those in the 20-year follow-up. Additionally, as part of the larger longitudinal and multidisciplinary Raine Study, a myriad of measures have been 
collected from this sample of young adults since their prenatal periods. This provides us with an excellent resource for evaluating the relationships between ocular health or parameters and systemic, environmental or genetic factors. The longitudinal nature of the study also enables assessments of environmental factors at 20 years in relation to eye outcomes at 27 - and 28 years. This is advantageous over cross-sectional observations as it allows us to infer causality with increased confidence.

An additional strength of the Raine Study is that the Gen2 participants (the current cohort), have been found to be generally representative of young Australians in WA at the 20 -year follow-up. ${ }^{62}$ However, the representativeness of the cohort at the 27- and 28-year follow-ups has not been examined. Nonetheless, a high proportion $(81 \%)$ of those participating in the 20-year follow-up also participated in the later follow-ups, which allows some confidence that the estimates of incidence and prevalence are generalisable to the WA young adult population.

Attrition may be a main limitation of the study. As well as a reducing sample size, this may result in loss-tofollow-up bias. From the time of the study inception in 1989 to the follow-up at 20-year, the number of 'active' participants decreased from 2868 to 2135 (-25.6\%). Between the 20- and 27-year follow-ups, the number of 'active participants' decreased by $6.7 \%$, and a further decrease by $0.4 \%$ occurred between the 27 - and 28 -year time points. Nonetheless, the dropout rates for the Raine Study have been low ${ }^{62}$ compared with many other longitudinal studies. ${ }^{119-121}$ With close to 2000 active participants in this 28-year follow-up, we still anticipate data being available for longitudinal analysis on a sample of approximately 1000 individuals. At approximately 28 years of age, this cohort of young adults is likely to have family and work commitments that could be prioritised over research participation. To accommodate their schedules, participants' visits are frequently planned after office hours, including on weeknights, weekends and public holidays; this has historically been shown to be helpful for participants. While participant retention will continue to be a challenge, especially with longer term follow-up and participant relocations, communication technology is continuously improving, which will allow us to better contact participants and schedule them for visits. Social media, emails and mobile phones texts are especially useful in contacting participants who have not been seen in a long time or are currently living in other states or overseas.

Another potential limitation of these follow-ups is the lack of cycloplegic refraction at the 27-year follow-up. Therefore, the 1-year incidence of refractive error (between the 27-year and 28-year visits) would have to be calculated based on the non-cycloplegic refractions, which may result in an overestimation of myoia and/or underestimation of hyperopia rates. Furthermore, for OCT imaging, while we were able to enter keratometry readings, this parameter will be corrected for in the statistical analyses as appropriate.

\section{ETHICS AND DISSEMINATION}

The 20-, 27-, and 28-year follow-ups of the Raine Study were approved by the University of Western Australia's Human Research Ethics committee. The studies are conducted in accordance with the tenets of the Declaration of Helsinki and informed consent is obtained from all participants prior to participation.

On completion of the study data collection and analyses, findings will be published in health or medical peer-reviewed journals and will be disseminated to the Raine Study participants. Additionally, the research will be presented in international and national conferences. The Raine Study has an Annual Scientific Meeting during which the multidisciplinary team of researchers that utilises data from the Raine Study gather to present their findings. Raine Study participants are also invited to this Annual Scientific Meeting.

\section{SUMMARY}

In this paper, we described the protocol for the longitudinal eye health assessments for the Raine Study follow-up. The outcomes from these studies will provide important information on longitudinal change in the eye health and parameters in a general population of Australian young adults, providing normative values of age-related change in ocular parameters. Additionally, the follow-up studies will provide an update on the prevalence of refractive errors and other ocular conditions in young adults in Australia, as well as incidence of eye conditions across the 1 - and 8-year follow-up periods.

\section{Author affiliations}

${ }^{1}$ Centre for Ophthalmology and Visual Science, University of Western Australia, Nedlands, Western Australia, Australia

${ }^{2}$ Lions Eye Institute, Nedlands, Western Australia, Australia

${ }^{3}$ Single Cell and Computational Genomics Lab, Garvan Institute of Medical Research, Darlinghurst, New South Wales, Australia

${ }^{4}$ Centre for Eye Research Australia Ltd, University of Melbourne, Royal Victorian Eye and Ear Hospital, East Melbourne, Victoria, Australia

${ }^{5}$ Department of Ophthalmology, Royal Perth Hospital, Perth, Western Australia, Australia

${ }^{6}$ School of Medicine, Menzies Research Institute Tasmania, University of Tasmania, Hobart, Tasmania, Australia

${ }^{7}$ Department of Twin Research \& Genetic Epidemiology, King's College London, London, UK

${ }^{8}$ School of Physiotherapy and Exercise Science, Curtin University, Perth, Western Australia, Australia

${ }^{9}$ Centre for Sleep Science, School of Human Sciences, University of Western Australia, Crawley, Western Australia, Australia

${ }^{10}$ Sir Charles Gairdner Hospital, West Australian Sleep Disorders Research Institute, Nedlands, Western Australia, Australia

${ }^{11}$ Genetics and Population Health, Queensland Institute of Medical Research - QIMR, Brisbane, Queensland, Australia

${ }^{12}$ University of Sydney, Sydney, New South Wales, Australia

${ }^{13}$ Australian National University, Research School of Population Health, College of

Health and Medicine, Canberra, Australian Capital Territory, Australia

${ }^{14}$ School of Optometry and Vision Science, Cardiff University, Cardiff, UK

${ }^{15}$ Singapore Eye Research Institute, Singapore

${ }^{16}$ Yong Loo Lin School of Medicine, National University of Singapore, Singapore

${ }^{17}$ Department of Ophthalmology, University of New South Wales, Sydney, New South Wales, Australia 
${ }^{18}$ State Key Laboratory of Ophthalmology, Zhongshan Ophthalmic Center, Sun YatSen University, Guangzhou, China

Acknowledgements We would like to acknowledge Raine Study staff, the Lions Eye Institute's staff and medical students who assisted in the study, and the Raine Study research participants and their families. We would additionally like to thank Professor Cathy Williams and Dr Sandra Staffieri for their input on the manuscript

Contributors SS-YL, SY and DAM were involved in the conception and design of the manuscript, with SS-YL responsible for the initial draft. DAM, SY, SSYL, GL, FKC, LMS and PRE were responsible for the conception, design, and implementation of the eye examination in the 27-year and/or 28-year follow-ups of the Raine Study. SS-YL, GL, DAM, JC, FN, SY, FKC, LMS and PRE are involved in the data collection for the eye examination in the 27-year and/or 28-year follow-ups of the Raine Study. PGS is the main statistician for the study. Funding was obtained by DAM, FKC, AWH, CH, SM, KAR, RML, MH, JAG, LMS, MTC, S-MS and PRE.

Funding The core management of the Raine Study is funded by the University of Western Australia, Australia; the Telethon Institute for Child Health Research, Australia; Raine Medical Research Foundation, Australia; Women's and Infant's Research Foundation, Australia; Curtin University, Australia; Murdoch University, Australia; Edith Cowan University, Australia; and the University of Notre Dame, Australia. The Generation-2 20-year follow-up of the Raine Study was funded by the National Health and Medical Research Council (NHMRC), Australia: project grant no.: 1021 105. The Generation-2 28-year follow-up of the Raine Study was funded by the NHMRC, Australia: project grants 1121979 and 1126 494. The NHMRC additionally supported SY (Early Career Fellowship), PGS (Early Career Fellowship), FKC (MRFF Career Development Fellowship), AWH (Practitioner Fellowship), SM (Senior Research Fellowship) and PRE (Senior Research Fellowship)

Competing interests None declared.

Patient consent for publication Not required.

Provenance and peer review Not commissioned; externally peer reviewed.

Open access This is an open access article distributed in accordance with the Creative Commons Attribution Non Commercial (CC BY-NC 4.0) license, which permits others to distribute, remix, adapt, build upon this work non-commercially, and license their derivative works on different terms, provided the original work is properly cited, appropriate credit is given, any changes made indicated, and the use is non-commercial. See: http://creativecommons.org/licenses/by-nc/4.0/.

\section{ORCID iDs}

Samantha Sze-Yee Lee http://orcid.org/0000-0001-6635-1098

Gareth Lingham http://orcid.org/0000-0002-8957-0733

Robyn M Lucas http://orcid.org/0000-0003-2736-3541

Jeremy A Guggenheim http://orcid.org/0000-0001-5164-340X

\section{REFERENCES}

1 Mathews PM, Rubin GS, McCloskey M, et al. Severity of vision loss interacts with word-specific features to impact out-loud reading in glaucoma. Invest Ophthalmol Vis Sci 2015;56:1537-45

2 Ramulu PY, Swenor BK, Jefferys JL, et al. Difficulty with outloud and silent reading in glaucoma. Invest Ophthalmol Vis Sci 2013;54:666-72.

3 Varadaraj V, Lesche S, Ramulu PY, et al. Reading speed and reading comprehension in age-related macular degeneration. $\mathrm{Am} \mathrm{J}$ Ophthalmol 2018;186:138-43.

4 Weih L, McCarty CA, Taylor HR. Functional implications of vision impairment. Clin Exp Ophthalmol 2000;28:153-5.

5 Owsley C, McGwin G. Vision and driving. Vision Res 2010;50:2348-61.

6 Lee SS-Y, Black AA, Wood JM. Scanning behavior and daytime driving performance of older adults with glaucoma. J Glaucoma 2018;27:558-65.

7 Kostyra E, Żakowska-Biemans S, Śniegocka K, et al. Food Shopping, sensory determinants of food choice and meal preparation by visually impaired people. obstacles and expectations in daily food experiences. Appetite 2017;113:14-22.

8 Smith ND, Crabb DP, Garway-Heath DF. An exploratory study of visual search performance in glaucoma. Ophthalmic Physiol Opt 2011;31:225-32.

9 Sippel K, Kasneci E, Aehling K, et al. Binocular glaucomatous visual field loss and its impact on visual exploration--a supermarket study. PLoS One 2014;9:e106089.
10 Nirmalan PK, Tielsch JM, Katz J, et al. Relationship between vision impairment and eye disease to vision-specific quality of life and function in rural India: the Aravind comprehensive eye survey. Invest Ophthalmol Vis Sci 2005;46:2308-12.

11 Rahi JS, Cumberland PM, Peckham CS, et al. Visual impairment and vision-related quality of life in working-age adults: findings in the 1958 British birth cohort. Ophthalmology 2009;116:270-4.

12 Ramulu PY, Hochberg C, Maul EA, et al. Glaucomatous visual field loss associated with less travel from home. Optom Vis Sci 2014;91:187-93.

13 Fenwick EK, Ong PG, Man REK, et al. Association of vision impairment and major eye diseases with mobility and independence in a Chinese population. JAMA Ophthalmol 2016;134:1087-93.

14 Bourne RRA, Flaxman SR, Braithwaite T, et al. Magnitude, temporal trends, and projections of the global prevalence of blindness and distance and near vision impairment: a systematic review and metaanalysis. Lancet Glob Health 2017;5:e888-97.

15 Forward H, Hewitt AW, Mackey DA. Missing X and Y: a review of participant ages in population-based eye studies. Clin Exp Ophthalmol 2012;40:305-19.

16 Klein BEK, Klein R, Knudtson MD. Intraocular pressure and systemic blood pressure: longitudinal perspective: the Beaver dam eye study. Br J Ophthalmol 2005;89:284-7.

17 Klein BEK, Klein R, Lee KE, et al. Incidence of age-related cataract over a 15-year interval the Beaver dam eye study. Ophthalmology 2008; $115: 477-82$

18 Klein BEK, Moss SE, Klein R, et al. Associations of visual function with physical outcomes and limitations 5 years later in an older population: the Beaver dam eye study. Ophthalmology 2003;110:644-50.

19 Klein R, Klein BE, Jensen SC, et al. The five-year incidence and progression of age-related maculopathy: the Beaver dam eye study. Ophthalmology 1997:104:7-21.

20 Joachim N, Mitchell P, Burlutsky G, et al. The incidence and progression of age-related macular degeneration over 15 years: the blue Mountains eye study. Ophthalmology 2015;122:2482-9.

21 Tan AG, Mitchell P, Flood VM, et al. Antioxidant nutrient intake and the long-term incidence of age-related cataract: the blue Mountains eye study. Am J Clin Nutr 2008;87:1899-905.

22 McCarty CA, Nanjan MB, Taylor HR. Vision impairment predicts 5 year mortality. Br J Ophthalmol 2001;85:322-6.

23 Taylor HR, McCarty CA, Nanjan MB. Vision impairment predicts five-year mortality. Trans Am Ophthalmol Soc 2000;98:91-6.

24 Rosman M, Zheng Y, Wong W, et al. Singapore Malay eye study: rationale and methodology of 6-year follow-up study (SiMES-2). Clin Exp Ophthalmol 2012;40:557-68.

25 Hennis AJ, Wu S-Y, Nemesure B, et al. Nine-Year incidence of visual impairment in the Barbados eye studies. Ophthalmology 2009:116:1461-8

26 Leske MC, Wu S-Y, Nemesure B, et al. Nine-Year incidence of lens opacities in the Barbados eye studies. Ophthalmology 2004:111:483-90

27 Nemesure B, Wu S-Y, Hennis A, et al. Nine-Year incidence and risk factors for pterygium in the Barbados eye studies. Ophthalmology 2008; $115: 2153-8$

28 van Leeuwen R, Klaver CCW, Vingerling JR, et al. The risk and natural course of age-related maculopathy: follow-up at $61 / 2$ years in the Rotterdam study. Arch Ophthalmol 2003;121:519-26.

29 Christ SL, Zheng DD, Swenor BK, et al. Longitudinal relationships among visual acuity, daily functional status, and mortality: the Salisbury eye evaluation study. JAMA Ophthalmol 2014:132:1400-6.

30 Klein BE, Klein R, Lee KE. Incidence of age-related cataract: the Beaver dam eye study. Arch Ophthalmol 1998;116:219-25.

31 Klein BEK, Klein R, Lee KE. Incidence of age-related cataract over a 10-year interval: the Beaver dam eye study. Ophthalmology 2002:109:2052-7.

32 Klein BE, Klein R, Lee KE, et al. Risk of incident age-related eye diseases in people with an affected sibling: The Beaver Dam Eye Study. Am J Epidemiol 2001:154:207-11.

33 Leske MC, Connell AM, Wu SY, et al. Incidence of open-angle glaucoma: the Barbados eye studies. The Barbados eye studies group. Arch Ophthalmol 2001;119:89-95.

34 Leske MC, Wu S-Y, Hennis A, et al. Nine-Year incidence of age-related macular degeneration in the Barbados eye studies. Ophthalmology 2006;113:29-35.

35 Leske MC, Wu S-Y, Hyman L, et al. Four-Year incidence of visual impairment: Barbados incidence study of eye diseases. Ophthalmology 2004;111:118-24.

36 Kanthan GL, Wang JJ, Burlutsky G, et al. Exogenous oestrogen exposure, female reproductive factors and the long-term incidence 
of cataract: the blue Mountains eye study. Acta Ophthalmol 2010;88:773-8.

37 Kanthan GL, Wang JJ, Rochtchina E, et al. Ten-Year incidence of age-related cataract and cataract surgery in an older Australian population. the blue Mountains eye study. Ophthalmology 2008;115:808-14.

38 Wang JJ, Rochtchina E, Lee AJ, et al. Ten-Year incidence and progression of age-related maculopathy: the blue Mountains eye study. Ophthalmology 2007;114:92-8.

39 Dimitrov PN, Mukesh BN, McCarty CA, et al. Five-Year incidence of bilateral cause-specific visual impairment in the Melbourne visual impairment project. Invest Ophthalmol Vis Sci 2003;44:5075-81.

40 McCarty DJ, Fu CL, Harper CA, et al. Five-Year incidence of diabetic retinopathy in the Melbourne visual impairment project. Clin Exp Ophthalmol 2003;31:397-402.

41 Mukesh BN, Dimitrov PN, Leikin S, et al. Five-Year incidence of age-related maculopathy ${ }^{*} 1$ The visual impairment project. Ophthalmology 2004;111:1176-82.

42 Attebo K, Ivers RQ, Mitchell P. Refractive errors in an older population: the blue Mountains eye study. Ophthalmology 1999;106:1066-72.

43 Attebo K, Mitchell P, Smith W. Visual acuity and the causes of visual loss in Australia. The blue Mountains eye study. Ophthalmology 1996;103:357-64

44 Mitchell P, Smith W, Attebo K, et al. Prevalence of openangle glaucoma in Australia. the blue Mountains eye study. Ophthalmology 1996;103:1661-9.

45 Panchapakesan J, Hourihan F, Mitchell P. Prevalence of pterygium and pinguecula: the blue Mountains eye study. Aust N $Z J$ Ophthalmol 1998;26 Suppl 1:S2-5.

46 Klein R, Meuer SM, Knudtson MD, et al. The epidemiology of progression of pure geographic atrophy: the Beaver dam eye study. Am J Ophthalmol 2008;146:692-9.

47 Klein R, Myers CE, Lee KE, et al. Small drusen and age-related macular degeneration: the Beaver dam eye study. J Clin Med 2015;4:425-40.

48 Leske MC, Wu SY, Nemesure B, et al. Incidence and progression of lens opacities in the Barbados eye studies. Ophthalmology 2000;107:1267-73.

49 SY W, Nemesure B, Hennis A, et al. Barbados eye studies G. nineyear changes in intraocular pressure: the Barbados eye studies. Arch Ophthalmol 2006;124:1631-6.

50 Zahari M, Mukesh BN, Rait JL, et al. Progression of visual field loss in open angle glaucoma in the Melbourne visual impairment project. Clin Exp Ophthalmol 2006;34:20-6.

51 Davidson S, Quinn GE. The impact of pediatric vision disorders in adulthood. Pediatrics 2011;127:334-9.

52 Kinge B, Midelfart A. Refractive changes among Norwegian university students- A three-year longitudinal study. Acta Ophthalmol Scand 1999;77:302-5.

53 Kinge B, Midelfart A, Jacobsen G, et al. Biometric changes in the eyes of Norwegian university students- A three-year longitudinal study. Acta Ophthalmol Scand 1999;77:648-52.

54 Jorge J, Almeida JB, Parafita MA. Refractive, biometric and topographic changes among Portuguese university science students: a 3-year longitudinal study. Ophthalmic Physiol Opt 2007;27:287-94.

55 Jorge J, de Almeida JB, Parafita MA. Binocular vision changes in university students: a 3-year longitudinal study. Optom Vis Sci 2008;85:E999-1006.

56 Kinge B, Midelfart A, Jacobsen G, et al. The influence of near-work on development of myopia among university students. A three-year longitudinal study among engineering students in Norway. Acta Ophthalmol Scand 2000;78:26-9.

57 Mirshahi A, Ponto KA, Hoehn R, et al. Myopia and level of education: results from the Gutenberg health study. Ophthalmology 2014;121:2047-52.

58 Morgan IG, French AN, Rose KA. Intense schooling linked to myopia. BMJ 2018;361:k2248

59 Williams KM, Bertelsen G, Cumberland P, et al. Increasing prevalence of myopia in Europe and the impact of education. Ophthalmology 2015;122:1489-97.

60 Scheiman M, Gwiazda J, Zhang Q, et al. Longitudinal changes in corneal curvature and its relationship to axial length in the correction of myopia evaluation trial (comet) cohort. J Optom 2016;9:13-21.

61 McKnight CM, Newnham JP, Stanley FJ, et al. Birth of a cohort--the first 20 years of the Raine study. Med J Aust 2012;197:608-10.

62 Straker L, Mountain J, Jacques A, et al. Cohort profile: the Western Australian pregnancy cohort (Raine) Study-Generation 2. Int $J$ Epidemiol 2017;46
63 Yazar S, Forward H, McKnight CM, et al. Raine eye health study: design, methodology and baseline prevalence of ophthalmic disease in a birth-cohort study of young adults. Ophthalmic Genet 2013;34:199-208.

64 Sanfilippo PG, Huynh E, Yazar S, et al. Spectral-Domain optical coherence Tomography-Derived characteristics of Bruch membrane opening in a young adult Australian population. Am J Ophthalmol 2016;165:154-63.

65 McKnight CM, Sherwin JC, Yazar S, et al. Myopia in young adults is inversely related to an objective marker of ocular sun exposure: the Western Australian Raine cohort study. Am J Ophthalmol 2014:158:1079-85.

66 McKnight CM, Sherwin JC, Yazar S, et al. Pterygium and conjunctival ultraviolet autofluorescence in young Australian adults: the Raine study. Clin Exp Ophthalmol 2015;43:300-7.

67 Yazar S, Hewitt AW, Black LJ, et al. Myopia is associated with lower vitamin D status in young adults. Invest Ophthalmol Vis Sci 2014:55:4552-9.

68 Lee SSY, Yazar S, Pasquale LR, et al. The relationship between optic disc parameters and female reproductive factors in young women. Asia Pac J Ophthalmol 2019;8:224-8.

69 Forward H, Yazar S, Hewitt AW, et al. Multiple prenatal ultrasound scans and ocular development: 20-year follow-up of a randomized controlled trial. Ultrasound Obstet Gynecol 2014;44:166-70.

70 Yazar S, Hewitt AW, Forward H, et al. Early anesthesia exposure and the effect on visual acuity, refractive error, and retinal nerve fiber layer thickness of young adults. J Pediatr 2016;169:256-9.

71 Yazar S, Cuellar-Partida G, McKnight CM, et al. Genetic and environmental factors in conjunctival UV autofluorescence. JAMA Ophthalmol 2015;133:406-12.

72 Mackey DA, Warrington NM, Hewitt AW, et al. Role of the Tcf4 gene intronic variant in normal variation of corneal endothelium. Cornea 2012;31:162-6.

73 Webb TR, Matarin M, Gardner JC, et al. X-Linked megalocornea caused by mutations in CHRDL1 identifies an essential role for ventroptin in anterior segment development. Am J Hum Genet 2012;90:247-59.

74 Mishra A, Yazar S, Hewitt AW, et al. Genetic variants near PDGFRA are associated with corneal curvature in Australians. Invest Ophthalmol Vis Sci 2012;53:7131-6.

75 Yazar S, Mishra A, Ang W, et al. Interrogation of the platelet-derived growth factor receptor alpha locus and corneal astigmatism in Australians of northern European ancestry: results of a genomewide association study. Mol Vis 2013;19:1238-46.

76 Guggenheim JA, McMahon G, Northstone K, et al. Birth order and myopia. Ophthalmic Epidemiol 2013;20:375-84.

77 Hysi PG, Cheng C-Y, Springelkamp H, et al. Genome-Wide analysis of multi-ancestry cohorts identifies new loci influencing intraocular pressure and susceptibility to glaucoma. Nat Genet 2014;46:1126-30.

78 Li Q, Wojciechowski R, Simpson CL, et al. Genome-Wide association study for refractive astigmatism reveals genetic codetermination with spherical equivalent refractive error: the cream Consortium. Hum Genet 2015;134:131-46.

79 Sanfilippo PG, Yazar S, Kearns L, et al. Distribution of astigmatism as a function of age in an Australian population. Acta Ophthalmol 2015;93:e377-85

80 Springelkamp H, Mishra A, Hysi PG, et al. Meta-Analysis of genome-wide association studies identifies novel loci associated with optic disc morphology. Genet Epidemiol 2015;39:207-16.

81 Cuellar-Partida G, Springelkamp H, Lucas SEM, et al. Wnt10A exonic variant increases the risk of keratoconus by decreasing corneal thickness. Hum Mol Genet 2015;24:5060-8.

82 Fan Q, Verhoeven VJM, Wojciechowski R, et al. Meta-Analysis of gene-environment-wide association scans accounting for education level identifies additional loci for refractive error. Nat Commun 2016;7:11008.

83 Fan Q, Guo X, Tideman JWL, et al. Childhood gene-environment interactions and age-dependent effects of genetic variants associated with refractive error and myopia: the cream Consortium. Sci Rep 2016;6:25853.

84 Huynh E, Bukowska DM, Yazar S, et al. Quantification of sun-related changes in the eye in conjunctival ultraviolet autofluorescence images. J Med Imaging 2016;3:034001.

85 Tideman JWL, Fan Q, Polling JR, et al. When do myopia genes have their effect? comparison of genetic risks between children and adults. Genet Epidemiol 2016;40:756-66.

86 Yazar S, Hewitt AW, Forward H, et al. Comparison of monochromatic aberrations in young adults with different visual acuity and refractive errors. J Cataract Refract Surg 2014;40:441-9. 
87 Mountford JK, Davies WIL, Griffiths LR, et al. Differential stability of variant OPN1LW gene transcripts in myopic patients. Mol Vis 2019;25:183-93.

88 Fernandes P, Diaz-Rey JA, Queiros A, et al. Comparison of the ICareR rebound tonometer with the Goldmann tonometer in a normal population. Oph Phys Optics 2005;25:436-40.

89 Abraham LM, Epasinghe NCR, Selva D, et al. Comparison of the ICARE rebound tonometer with the Goldmann applanation tonometer by experienced and inexperienced tonometrists. Eye 2008;22:503-6.

90 Jia Y, Tan O, Tokayer J, et al. Split-spectrum amplitudedecorrelation angiography with optical coherence tomography. Opt Express 2012;20:4710-25.

91 English D, MacLennan R, Rivers J, et al. Epidemiological studies of melanocytic naevi:Epidemiological studies of melanocytic naevi: protocol for identifying and recording naevi. Lyon France: IARC International report, 1990: 90.

92 Holman CD, Armstrong BK, Evans PR, et al. Relationship of solar keratosis and history of skin cancer to objective measures of actinic skin damage. Br J Dermatol 1984;110:129-38.

93 Holden BA, Fricke TR, Wilson DA, et al. Global prevalence of myopia and high myopia and temporal trends from 2000 through 2050. Ophthalmology 2016;123:1036-42.

94 Flitcroft DI, He M, Jonas JB, et al. IMI - Defining and Classifying Myopia: A Proposed Set of Standards for Clinical and Epidemiologic Studies. Invest Ophthalmol Vis Sci 2019;60:M20-30.

95 Krantz EM, Cruickshanks KJ, Klein BEK, et al. Measuring refraction in adults in epidemiological studies. Arch Ophthalmol 2010;128:88-92.

96 Zeger SL, Liang KY, Albert PS. Models for longitudinal data: a generalized estimating equation approach. Biometrics 1988;44:1049-60.

97 Lu N, Tang W, He H, et al. On the impact of parametric assumptions and robust alternatives for longitudinal data analysis. Biom $J$ 2009;51:627-43.

98 Yotsukura $\mathrm{E}$, Torii $\mathrm{H}$, Inokuchi M, et al. Current prevalence of myopia and association of myopia with environmental factors among schoolchildren in Japan. JAMA Ophthalmol 2019;137:1233.

99 Bez D, Megreli J, Bez M, et al. Association between type of educational system and prevalence and severity of myopia among male adolescents in Israel. JAMA Ophthalmol 2019;137:887.

100 Lee SSY, McArdle N, Sanfilippo PG, et al. Associations between optic disc measures and obstructive sleep apnea in young adults. Ophthalmology 2019;126:1372-84.

101 Taylor HR, Livingston PM, Stanislavsky YL, et al. Visual impairment in Australia: distance visual acuity, near vision, and visual field findings of the Melbourne visual impairment project. $A m \mathrm{~J}$ Ophthalmol 1997;123:328-37.

102 Livingston PM, Carson CA, Stanislavsky YL, et al. Methods for a population-based study of eye disease: the Melbourne visual impairment project. Ophthalmic Epidemiol 1994;1:139-48.

$103 \mathrm{Li} \mathrm{S}-\mathrm{M}$, Li H, Li S-Y, et al. Time outdoors and myopia progression over 2 years in Chinese children: the Anyang childhood eye study. Invest Ophthalmol Vis Sci 2015;56:4734-40.
104 Zhou W-J, Zhang Y-Y, Li H, et al. Five-Year progression of refractive errors and incidence of myopia in school-aged children in Western China. J Epidemiol 2016;26:386-95.

105 Read SA, Collins MJ, Vincent SJ. Light exposure and eye growth in childhood. Invest Ophthalmol Vis Sci 2015;56:6779-87.

106 Shih Y-F, Chiang T-H, Hsiao CK, et al. Comparing myopic progression of urban and rural Taiwanese schoolchildren. Jpn J Ophthalmol 2010;54:446-51

107 Fan DSP, Lam DSC, Lam RF, et al. Prevalence, incidence, and progression of myopia of school children in Hong Kong. Invest Ophthalmol Vis Sci 2004;45:1071-5.

108 Feuer WJ, Budenz DL, Anderson DR, et al. Topographic differences in the age-related changes in the retinal nerve fiber layer of normal eyes measured by Stratus optical coherence tomography. $J$ Glaucoma 2011;20:133-8.

109 Alasil T, Wang K, Keane PA, et al. Analysis of normal retinal nerve fiber layer thickness by age, sex, and race using spectral domain optical coherence tomography. J Glaucoma 2013;22:532-41.

110 Galgauskas S, Juodkaite G, Tutkuvienè J. Age-Related changes in central corneal thickness in normal eyes among the adult Lithuanian population. Clin Interv Aging 2014;9:1145-51.

111 Galgauskas S, Norvydaitė D, Krasauskaite D, et al. Age-Related changes in corneal thickness and endothelial characteristics. Clin Interv Aging 2013;8:1445-50.

112 Siu A, Herse P. The effect of age on human corneal thickness. statistical implications of power analysis. Acta Ophthalmol 1993;71:51-6

113 Yee RW, Matsuda M, Schultz RO, et al. Changes in the normal corneal endothelial cellular pattern as a function of age. Curr Eye Res 1985;4:671-8.

114 Fledelius HC, Stubgaard M. Changes in refraction and corneal curvature during growth and adult life. Acta Ophthalmol 1986;64:487-91.

115 Goto T, Klyce SD, Zheng X, et al. Gender- and age-related differences in corneal topography. Cornea 2001;20:270-6.

116 Bowd C, Zangwill LM, Blumenthal EZ, et al. Imaging of the optic disc and retinal nerve fiber layer: the effects of age, optic disc area, refractive error, and gender. J Opt Soc Am A Opt Image Sci Vis 2002;19:197-207.

117 Alamouti B, Funk J. Retinal thickness decreases with age: an OCT study. Br J Ophthalmol 2003;87:899-901.

118 Girkin CA, McGwin G, Sinai MJ, et al. Variation in optic nerve and macular structure with age and race with spectral-domain optical coherence tomography. Ophthalmology 2011;118:2403-8.

119 Young AF, Powers JR, Bell SL. Attrition in longitudinal studies: who do you lose? Aust N Z J Public Health 2006;30:353-61.

120 Chatfield MD, Brayne CE, Matthews FE. A systematic literature review of attrition between waves in longitudinal studies in the elderly shows a consistent pattern of dropout between differing studies. J Clin Epidemiol 2005;58:13-19.

121 Cotter RB, Burke JD, Stouthamer-Loeber M, et al. Contacting participants for follow-up: how much effort is required to retain participants in longitudinal studies? Eval Program Plann 2005;28:15-21. 